\title{
New "News" for the News Model of the Spot Exchange Rate
}

\author{
Wenti Du \\ Akita International University, Japan \& Claremont Graduate University, USA \\ and \\ Eric J Pentecost \\ Loughborough University, UK \& Claremont Graduate University, USA
}

\begin{abstract}
The "News" model of the exchange rate, that received only weak support in the 1980s, is shown to be a verifiable model of the bilateral spot rate once the "news" is appropriately measured. Using market sentiment and policy uncertainty indices derived from big data for Japan, as "news" and survey data of agents' expectations of the spot rate one month ahead, the "News" model of the exchange rate is shown not to be rejected for the bilateral USD/JPY rate from June 2009 to December 2017.
\end{abstract}

June 2020

JEL Classification Nos: F31, F41, G15

Keywords: Big data, market sentiment, policy uncertainty, the "News" model of the exchange rate 


\section{Introduction}

The "News" version of the monetary model of the exchange rate developed in the early 1980s by Dornbusch (1980) and Frenkel (1981), initially received only weak support from the data (see also for example, Edwards, 1982, and Copeland, 1984), largely due to data deficiencies in measuring the news. In this letter the news is not represented by the residuals from an autoregressive model of the fundamental determinants of the exchange rate, as was formerly the case, but is innovatively measured by using big data to form indices of market sentiment or policy uncertainty (Baker et al 2016 and Arbatli et al 2019). Using these indices to capture the news - defined as unexpected events - together with survey data on agents' average expected spot rates for the US dollar/ Japanese Yen exchange rate, we show that the news model of the exchange rate is supported for the US dollar/Japanese Yen exchange rate over the period 2009-2017.

The rest of this paper is organised as follows: Section 2 outlines how the sentiment and policy uncertainty indices are constructed; Section 3 presents the news model of the exchange rate; and Section 4 discusses the empirical test results for the US dollar/Japanese Yen rate.

\section{The sentiment and policy uncertainty data}

The sentiment indices are derived from Thomson Reuters MarketPsych Indices (TRMI), which convert the unstructured information from mainstream news sources, such as The New York Times, The Wall Street Journal and The Financial Times, in addition to social media sources collected by MarketPsych Data and LexisNexis, into big data through text analysis. The TRMI indices are updated by the minute and over 2 million articles are processed daily, contributing to the TRMI feed within minutes of their publication.

Each TRMI is composed of a combination of variables. First, the absolute values of all TRMI-contributing variables for all asset constituents over the past 24 hours are determined. These absolute values are then summed for all constituent elements. This sum is called the "Buzz," and it is published in conjunction with each asset's TRMIs. More formally, where $V$ is the set of all variables underlying any TRMI of the asset class, given that $v$ is a component of 
$V$ such that $v \in V$, where $\alpha$ denotes an asset, and where $C(\alpha)$ is the set of all constituents of $\alpha$, we can define the Buzz of $\alpha$ as the following:

$$
\operatorname{Buzz}(\alpha)=\sum_{c \in C(\alpha), v \in V}\left|V_{c, v}\right|
$$

According to Peterson (2016), each TRMI is then constructed as a ratio between the sum of all relevant variables, as words and terms, such that

$$
\operatorname{TRMI}_{t}(\alpha)=\frac{\sum_{c \in C(\alpha), v \in V}\left(I(t, v) \times \operatorname{PsychVar}_{v}(c)\right)}{\operatorname{Buzz}(\alpha)}
$$

where $\quad I(t, v)= \begin{cases}+1 & \text { if additive } \\ -1 & \text { if subtractive }\end{cases}$

This paper employs the sentiment indices from the countries TRMI indices for Japan between June 1, 2009 to December 31, 2017, which ranges from -1 to 1.

The alternative measure of news used in this paper is that for policy uncertainty derived by Arbatli et al (2019) for Japan, using the methodology of Baker et al (2016). This approach aims to capture uncertainty about who will make relevant economic policy decisions, when and what policy actions will be taken, and the economic effects of such policy actions. To construct the overall measure of economic policy uncertainty (EPU), articles are counted in four major Japanese newspapers (Yomiuri Shimbun, Asahi Shimbun, Mainichi Shimbun and Nihon Keizai Shimbun) that contain at least one term in each of three categories: (E) 'economic' or 'economy'; (P) 'tax,' 'government spending', 'regulation,' 'Bank of Japan' or certain other policy-related terms; and (U) 'uncertain' or 'uncertainty'. The EPU is scaled by the number of articles in the same newspaper and month, standardize each paper's series of scaled counts to the same variability over time, adjust for seasonality, and then average across papers by month to obtain the EPU index. The EPU index ranges from zero to positive infinity, which we normalise to range from 0 to 1 to be consistent with the sentiments index.

Uncertainty indices for monetary policy, fiscal policy, trade policy and exchange rate policy are computed in a similar fashion, specifying additional criteria for those articles that contain the triple of terms about the economy, policy, and uncertainty. All the measures of policy uncertainty are available monthly from 1987. 


\section{The News Model}

The key result from the monetary model of the exchange rate is that the log of the spot exchange rate, $s_{t}$, is linearly related to the log of the monetary fundamentals $m_{t}$, where $m$ is a vector of relative money supplies and outputs for the home and foreign countries and the relationship is written as:

$$
s_{t}=\beta m_{t}+u_{t}
$$

where $\beta$ is the vector of coefficients and $u_{t}$ is a random error term with $E_{t}\left(u_{t}\right)=0$ and $E\left(u_{t}^{2}\right)=\sigma_{u}^{2}$.Taking expectations at time t-1 the model becomes: $E_{t-1} s_{t}=\beta E_{t-1} m_{t}$, which when subtracted from (3) gives the news model as:

$$
s_{t}-E_{t-1}\left(s_{t}\right)=\beta\left[m_{t}-E_{t-1}\left(m_{t}\right)\right]+u_{t}
$$

where the term in square brackets is the news: that is, the difference between the fundamentals and the expected value of the fundamentals based on information at time $t-1$. The news term is the residual, $\hat{e}_{t}$, traditionally derived from the regression of the vector $m_{t}$ on lagged values of itself and any other relevant observable information available to market makers at time $\mathrm{t}-1$. Therefore, the empirical version of (4) can be written as:

$$
\left(s_{t}-{ }_{t-1} E\left(s_{t}\right)\right)=\alpha+\beta \hat{e}_{t}+u_{t}
$$

where a statistically significant $\beta$ coefficient is deemed to confirm the validity of the model.

The sentiment index used here allows the partition of the news term into good news and bad news. In the case of bad news, $\beta>0$, since a depreciation is expected following bad news, whereas in the case of good news an appreciation is expected so $\beta<0$. When we use the policy uncertainty measures as the news, there are five specific overlapping measures relating to different aspects of policy uncertainty: economic policy, fiscal policy, monetary policy, trade policy and exchange rate policy. In each case the sign of the respective $\beta^{\prime}$ s depends on the overall balance of good and bad news on each metric over the sample.

Finally, to test the model we also make use of survey data from market agents collected by the Japan Center for International Finance (JICF) to measure the expected spot 
exchange rate one month ahead (see Ito, 1990), which is preferable to the use of the forward exchange rate, since this would also involve an implicit additional test of foreign exchange market efficiency (Copeland, 1984). The daily spot rate of USD/JPY is collected from Yahoo Finance in order to compute the dependent variable of the model - the log of the USD/JPY spot rate less the log of the agents expected spot exchange rate one month ahead.

\section{Empirical Analysis and Discussion}

The sample period is from June 2009 to December 2017, the data is monthly, with the spot exchange rate measured as the closing rate at the end of the month and the expected spot exchange rate series measured as the expected rate at the end of the next month. The dependent variable - the log of the spot rate less the log of the expected spot rate - was pretested for its time series properties which, as expected, was found to be strongly stationary, in that the null hypothesis of non-stationarity was strongly rejected, with an ADF statistic of -9.097 , compared to a critical value at 5 per cent of -2.902 . The model is therefore estimated by ordinary least squares (OLS).

Table 1 shows the OLS results for equation (5) and what we call the Market Sentiments Model (MSM) and the Policy Uncertainty Model (PUM) for the two alternative measures of the news. Both models are statistically significant, as shown by the respective F-statistics, although as expected of this class of exchange rate model, they both have relatively low explanatory power.

The MSM results show that good news leads to a statistically significant appreciation of the yen against the US dollar, whilst bad news although of wrong sign has no significant effect on the unanticipated change in the spot rate. The lack of significance following unexpected bad news may suggest that bad news is already built into the spot market rate, so that agents are inherently pessimistic over the sample period.

The PUM of the "news" shows that uncertainty about trade policy trends to depreciate the yen, whilst economic policy uncertainty appreciated the yen. These results are explained by the fact that movements in the index of trade policy uncertainty is closely linked to the US election in November 2017 in which the new President's policy of America first was deemed 
bad news for Japanese trade as he withdrew the US from the Trans-Pacific Partnership (TPP) trade agreement, which prevented it from becoming operational. BREXIT was also believed to be bad news for Japanese trade captured by trade policy uncertainty. There has been little uncertainty regarding Japanese monetary policy and exchange rate policy since the global financial crash of 2008-09 and so these uncertainty measures were unsurprisingly statistically insignificant. Perhaps more surprising was that fiscal policy uncertainty was only very marginally significant (at 15 per cent), although the index of overall economic policy uncertainty was highly significant (at 5 per cent), perhaps suggesting some multicollinearity between the fiscal policy uncertainty and overall economic policy uncertainty measures. Overall economic policy uncertainty gave rise to a stronger yen, in part due to the unexpected good news in June 2016 when Abe Shinzo confirmed the delay in the expected sales tax hike from April 2017 to October 2019.

We conclude that news events measured from big data are significant drivers of unexpected movements in spot exchange rates. News that is specifically related to various dimensions of economic policy uncertainty tend to give better fitting results than to that of general market sentiment, when it comes to explaining unexpected movements in the spot exchange rate. 


\section{References}

Arbatli, E. C., S. J. Davis, A. Ito, N. Miake and I. Saito (2019), "Policy Uncertainty in Japan," NBER, Working Paper No. 23411.

Baker, S. R., N. Bloom, and S. J. Davis, (2016), "Measuring Economic Policy Uncertainty," Quarterly Journal of Economics, 131, no. 4 (November), 1593-163.

Copeland, L.S. (1984), The Pound Sterling/US Dollar Exchange Rate and the "News", Economics Letters, 16, 109-13.

Dornbuch, R. (1980), Exchange rate economics: where do we stand? Brookings papers on Economic Activity, 1, 143-85.

Frenkel, J.A. (1981), Flexible exchange rates, prices and the role of "news": lessons from the 1970s, Journal of Political Economy, 89, 665-705.

Ito, T. (1990), Foreign exchange rate expectations: micro survey data, American Economic Review, 80, 434-49.

Peterson, R. L. (2016). Trading on Sentiment: The Power of Minds Over Markets. John Wiley \& Sons. 
Table 1: Results for the MSM and the PUM

\begin{tabular}{|c|c|c|}
\hline & $\begin{array}{c}\text { Market Sentiments } \\
\text { Model }\end{array}$ & $\begin{array}{c}\text { Policy Uncertainty } \\
\text { Model }\end{array}$ \\
\hline Constant & $\begin{array}{l}0.004[0.356] \\
(0.005)\end{array}$ & $\begin{array}{l}0.006[0.296] \\
(0.005)\end{array}$ \\
\hline Good news & $\begin{array}{l}-0.594[0.004] \\
(0.199)\end{array}$ & \\
\hline Bad news & $\begin{array}{l}-0.058[0.277] \\
(0.053)\end{array}$ & \\
\hline Economic policy uncertainty & & $\begin{array}{l}-0.105[0.068] \\
(0.057)\end{array}$ \\
\hline Fiscal policy uncertainty & & $\begin{array}{l}0.069[0.146] \\
(0.047)\end{array}$ \\
\hline Monetary policy uncertainty & & $\begin{array}{l}0.007[0.857] \\
(0.037)\end{array}$ \\
\hline Trade policy uncertainty & & $\begin{array}{l}0.051[0.048] \\
(0.025)\end{array}$ \\
\hline Exchange rate policy uncertainty & & $\begin{array}{l}-0.027[0.418] \\
(0.033)\end{array}$ \\
\hline \multirow[t]{2}{*}{ Diagnostic statistics } & $F[2,91]=4.44[0.014]$ & $F[5,8]=3.50[0.006]$ \\
\hline & $R^{2}=0.047$ & $\mathrm{R}^{2}=0.132$ \\
\hline
\end{tabular}

Key: The Dependent variable is the unexpected change in the spot USD/JPY exchange rate; robust standard errors are given in round brackets below the coefficients and the probability values in square brackets beside the coefficients. 